\title{
Measurement and convergence analysis of agricultural green development level in China
}

\author{
He Hui ${ }^{1}$, Wu Xiumin ${ }^{1 *}$ \\ 1211 Huimin Road, Wenjiang District, Chengdu City, Sichuan Province, China
}

\begin{abstract}
Based on the panel data of 30 provinces and regions (except Taiwan, Hong Kong, Macao and Tibet) from 2010 to 2019, this paper measures the green development level of agriculture in China by using critic- entropy weight combined weight method, and then uses $\sigma$ convergence and absolute $\beta$ convergence methods to test its change trend. Based on the research conclusions, countermeasures and suggestions were put forward to make up for the shortcomings, promote the exchange and cooperation between provinces and regions, and narrow the differences between provinces, in order to provide reference for policy formulation and promote the green development of agriculture in China.
\end{abstract}

\section{Introduction}

Since the reform and opening up, China's agriculture has achieved rapid development, the output of agricultural products has increased steadily, agricultural production conditions have been greatly improved, agricultural structure has been continuously optimized, farmers' income has continued to increase, and great achievements have been made. However, with the rapid development of agriculture, the agricultural environment has become a "red light", the quality of agricultural products has touched the "bottom line", and the supply of high-quality and safe agricultural products is insufficient, which is difficult to meet the growing needs of people for a better life ${ }^{1}$, which is the prominent expression of the major social contradiction in the agricultural field ${ }^{1}$. Therefore, it is of great significance to give full consideration to the cost of resources and environment in agricultural production, construct a reasonable evaluation index system of agricultural green development, and objectively evaluate and analyze the current situation of agricultural green development, which will gradually realize the transformation from traditional agriculture to green agriculture.

Green development contains the concept and thought of sustainable development. Since the concept of green development was extended to the field of agriculture, more and more studies have been conducted on the level of green development of agriculture. In terms of research content, scholars have constructed a series of different index systems to measure the level of agricultural green development according to their different understandings of the connotation of agricultural green development ${ }^{116}$. In terms of research methods, scholars mainly use principal component analysis, DPSIR model ${ }^{6}$, interval intuitionistic fuzzy dynamic programming model $^{6}$, analytic hierarchy process ${ }^{[7][16]}$, entropy value method ${ }^{[2]}$, combined weight analysis method ${ }^{[9]}$, entropy weight method ${ }^{[4]}$, etc., to measure and evaluate the level of agricultural green development.

Because of this, most of the existing studies still remain on the scientific measurement of the level of green agricultural development, and lack of further internal mechanism analysis. Since Baumol ${ }^{17}$ initiated the empirical study on the convergence of economic growth, convergence analysis has become a research hotspot and has been widely used in economic growth research ${ }^{1819}$, productivity research ${ }^{20}$ and energy and environment research ${ }^{2122}$. The green development of agriculture is closely related to resources and environment, but the research on convergence analysis in this area is still relatively lacking.

Based on this, this paper takes 30 provinces (Taiwan, Hong Kong, Macao and Tibet excluded) as the research object, and on the basis of measuring the level of agricultural green development, it further studies the convergence of agricultural green development level through $\sigma$ convergence test and absolute $\beta$ test, so as to enrich the research content of agricultural green development.

\section{Research methods, index system construction and data sources}

\subsection{Research methods}

\subsubsection{Critic-Entropy weight method combined weight method}

Some scholars find that critic is more comprehensive and objective after comparing various objective weighting methods ${ }^{2324}$. Critic method was proposed by Diakoulaki ${ }^{25}$ in 1995. This method measures the objective weight of 
indicators by evaluating their comparative strength and conflict. However, it is found that although Critic method can comprehensively measure the strength of contrast and conflict among indicators, it cannot measure the degree of dispersion among indicators, and entropy weight method can make up for this deficiency ${ }^{26}$. Based on this, this paper constructs a combined weighting method based on critic and entropy weight method. The main calculation steps are as follows: firstly, the positive and negative indicators in the index system are standardized to eliminate the possible impact of the dimensionless inconsistency of the indicators; Secondly, weight is given respectively based on Critic method and entropy weight method. Thirdly, the comprehensive weight is determined. Finally, the comprehensive score of agricultural green development level was calculated according to the comprehensive weight.

\subsubsection{Analysis of $\sigma$ convergence}

$\sigma$ convergence means that the degree of dispersion of agricultural green development levels in different provinces decreases with the passage of time, that is, the gap of agricultural green development between provinces shrinks. The specific formula is as follows:

$$
\delta_{t}=\sqrt{\frac{1}{n} \sum_{i=1}^{n}\left(\ln y_{i}-\frac{1}{n} \sum_{i=1}^{n} \ln y_{i t}\right)^{2}}
$$

Where, $y_{i t}$ is the level of agricultural green development in the $\mathrm{i}$ province in the $\mathrm{t}$ year, and $\mathrm{n}$ is the number of provinces and regions. If $\sigma_{\mathrm{t}+1}<\sigma_{\mathrm{t}}$, it indicates that there is $\sigma$ convergence in agricultural green development of 30 provinces and regions in China; If $\sigma_{t+1}>\sigma_{t}$, it indicates that there is no $\sigma$ convergence in agricultural green development of 30 provinces and regions in China.

\subsubsection{Absolute $\beta$ convergence analysis}

Absolute $\beta$ convergence is used to determine whether the provinces with low initial green agricultural development level will eventually converge with the provinces with high level of development over time, that is, the regions with low level of development tend to have a faster growth rate than the regions with high level of development, and the regions with low level of development have a "catch-up effect" approaching the regions with high level of development. Referring to the research of relevant scholars, the absolute $\beta$ convergence model in this paper is as follows:

$$
\frac{1}{T} \ln \left(X_{i, t}-X_{i, 0}\right)=\alpha+\beta X_{i, 0}+\varepsilon
$$

Whereinto, $\mathrm{T}$ is the research time span, represents the level of green agricultural development in I province in the initial year, and represents the average annual growth rate of green agricultural development in I province in the period of $T$. If $\beta<0$ and is statistically significant, it indicates that there is absolute $\beta$ convergence in the green development level of agriculture, otherwise, it does not exist.

\subsection{Construction of index system}

Reference to relevant domestic scholars research achievements, follow the principle of scientific, comprehensive and data availability ${ }^{27}$, the total index of green agricultural development level as the target layer, resource saving, output and high efficiency, environment friendly, green supply, rural development as a secondary indicators and 26 tertiary index, construct the index system (table 1).

Table1. Evaluation index system of agricultural green

\begin{tabular}{|c|c|c|}
\hline Category & Indicator & Direction \\
\hline \multirow{4}{*}{$\begin{array}{l}\text { Saving } \\
\text { resources } \\
\quad(\mathrm{SR})\end{array}$} & $\begin{array}{l}\text { Cultivated land } \\
\text { retention rate }(\%)\end{array}$ & + \\
\hline & \multirow{2}{*}{$\begin{array}{l}\text { Water consumption } \\
\text { per unit area }\left(\mathrm{m}^{3} / \mathrm{ha}\right)\end{array}$} & - \\
\hline & & + \\
\hline & $\begin{array}{l}\text { Coefficient of multiple } \\
\text { cropping of land }\end{array}$ & - \\
\hline \multirow{5}{*}{$\begin{array}{l}\text { Output } \\
\text { efficiency } \\
\text { (OE) }\end{array}$} & $\begin{array}{l}\text { Per unit area yield of } \\
\text { grain }(\mathrm{kg} / \mathrm{ha})\end{array}$ & + \\
\hline & $\begin{array}{l}\text { Yield of fruits and } \\
\text { vegetables }(\mathrm{kg} / \mathrm{ha})\end{array}$ & + \\
\hline & $\begin{array}{l}\text { Number of green food } \\
\text { labeling products per unit } \\
\text { area(1/10000 hectares })\end{array}$ & + \\
\hline & $\begin{array}{l}\text { Number of organic food } \\
\text { labeled products per unit } \\
\text { area( } 1 / 10000 \text { hectares })\end{array}$ & + \\
\hline & $\begin{array}{l}\text { Agricultural output value per } \\
\text { unit area(ten thousand } \\
\text { yuan/ha) }\end{array}$ & + \\
\hline \multirow{7}{*}{$\begin{array}{l}\text { Environment } \\
\text { friendly } \\
(\mathrm{EF})\end{array}$} & $\begin{array}{l}\text { Fertilizer application } \\
\text { intensity }(\mathrm{kg} / \mathrm{ha})\end{array}$ & - \\
\hline & $\begin{array}{l}\text { Pesticide application } \\
\text { intensity }(\mathrm{kg} / \mathrm{ha})\end{array}$ & - \\
\hline & $\begin{array}{l}\text { Agricultural film use } \\
\text { intensity }(\mathrm{kg} / \mathrm{ha})\end{array}$ & - \\
\hline & $\begin{array}{l}\text { Use intensity of agricultural } \\
\text { diesel oil }(\mathrm{kg} / \mathrm{ha})\end{array}$ & - \\
\hline & $\begin{array}{l}\text { Harmless disposal rate of } \\
\text { garbage }(\%)\end{array}$ & - \\
\hline & Forest coverage $(\%)$ & + \\
\hline & $\begin{array}{l}\text { Prevention and control rate } \\
\text { of forest pests and } \\
\text { rodents }(\%)\end{array}$ & - \\
\hline \multirow{4}{*}{$\begin{array}{l}\text { Green } \\
\text { supply } \\
\text { (GS) }\end{array}$} & $\begin{array}{l}\text { Market competitiveness of } \\
\text { green food }(\%)\end{array}$ & + \\
\hline & $\begin{array}{l}\text { Number of green food } \\
\text { certification units }\end{array}$ & + \\
\hline & $\begin{array}{l}\text { Organic food market } \\
\text { competitiveness }(\%)\end{array}$ & + \\
\hline & $\begin{array}{l}\text { Number of organic food } \\
\text { certification units }\end{array}$ & + \\
\hline \multirow{2}{*}{$\begin{array}{l}\text { Rural } \\
\text { development } \\
\text { (RD) }\end{array}$} & $\begin{array}{l}\text { Gross output value of } \\
\text { agriculture, forestry, animal } \\
\text { husbandry and fishery(One } \\
\text { hundred million yuan) }\end{array}$ & + \\
\hline & $\begin{array}{l}\text { Total power of agricultural } \\
\text { machinery per unit } \\
\text { area(Kilowatts per hectare) }\end{array}$ & + \\
\hline
\end{tabular}
development level. 


\begin{tabular}{|l|c|}
$\begin{array}{l}\text { Per capita disposable income } \\
\text { of rural residents(yuan) }\end{array}$ & + \\
\hline $\begin{array}{l}\text { Access rate of sanitary toilets } \\
\text { in rural areas(\%) }\end{array}$ & + \\
\hline $\begin{array}{l}\text { Per capita agricultural } \\
\text { GDP(Yuan/person) }\end{array}$ & + \\
\hline Rural economic status(\%) & + \\
\hline
\end{tabular}

\subsection{Data Sources}

Based on the availability of data, this study covers 30 Chinese provinces (except Tibet, Hong Kong, Taiwan and Macao). The data are mainly from the National Bureau of Statistics of China, China Rural Statistical Yearbook (2010-2020), Statistical Bulletin of Green Food (20102019), Statistical Bulletin of Organic Food (2010-2019), and statistical yearbooks of 30 provinces and autonomous regions (2010-2020).

\section{Agricultural green development level analysis}

\subsection{The national level}

As shown in Table 2, from 2010 to 2019, China's agricultural green development level continued to improve, and the growth rate was stable. The score of China's comprehensive agricultural green development index increased from 0.241 in 2010 to 0.310 in 2019, a cumulative increase of 0.069 , with an average annual growth rate of $2.40 \%-4.18 \%$. According to the scores of the five second-level indicators, the ranking is environment-friendly, rural development, output efficiency, green supply and resource conservation. Therefore, green supply and resource conservation are the weak links in China's agricultural green development.

Table2. Comprehensive indicators and secondary indicators of agricultural green development in China from 2010 to 2019

\begin{tabular}{|l|c|c|c|c|c|c|}
\hline year & AGD & SR & OE & EF & GS & RD \\
\hline $\mathbf{2 0 1 0}$ & 0.241 & 0.028 & 0.037 & 0.086 & 0.03 & 0.059 \\
\hline $\mathbf{2 0 1 1}$ & 0.247 & 0.028 & 0.038 & 0.086 & 0.03 & 0.065 \\
\hline $\mathbf{2 0 1 2}$ & 0.257 & 0.029 & 0.039 & 0.089 & 0.029 & 0.071 \\
\hline $\mathbf{2 0 1 3}$ & 0.263 & 0.028 & 0.04 & 0.091 & 0.028 & 0.075 \\
\hline $\mathbf{2 0 1 4}$ & 0.274 & 0.029 & 0.041 & 0.095 & 0.03 & 0.079 \\
\hline $\mathbf{2 0 1 5}$ & 0.282 & 0.029 & 0.044 & 0.096 & 0.03 & 0.083 \\
\hline $\mathbf{2 0 1 6}$ & 0.285 & 0.029 & 0.045 & 0.096 & 0.031 & 0.083 \\
\hline $\mathbf{2 0 1 7}$ & 0.292 & 0.03 & 0.047 & 0.098 & 0.033 & 0.086 \\
\hline $\mathbf{2 0 1 8}$ & 0.299 & 0.03 & 0.048 & 0.096 & 0.036 & 0.089 \\
\hline $\mathbf{2 0 1 9}$ & 0.31 & 0.03 & 0.051 & 0.095 & 0.038 & 0.096 \\
\hline
\end{tabular}

\subsection{The provincial level}

As shown in Table 3, there are significant differences in the level of agricultural green development between provinces and regions from 2010 to 2019 . Shandong has the highest score in the comprehensive index (0.417), while Guizhou has the lowest score (0.154). Among the 30 provinces and autonomous regions, the top five and bottom five are "Shandong, Beijing, Zhejiang, Fujian and Jiangsu" and "Ningxia, Chongqing, Qinghai, Shanxi and Guizhou".

Among them, the top five provinces and autonomous regions are all located in the eastern economically developed regions and have good performance under the second-level indicators, but their weak links and driving factors are significantly different. In terms of core drivers, Shandong is represented by green supply and rural development, Beijing is represented by resource conservation and output efficiency, and Fujian is represented by environmental friendliness. In terms of key weaknesses, resource conservation is seen in Shandong province, while green supply and rural development are seen in Beijing.

The bottom five provinces and regions are mainly located in the economically underdeveloped regions in western China, with significant differences in driving factors and weak links. Among them, Chongqing, Shanxi and Guizhou have no obvious driving factor, while the core driving factor for Ningxia and Qinghai is resource conservation, ranking the 3rd and 6th place respectively. In terms of weak links, the core weaknesses of Ningxia and Qinghai were in environmental friendliness, while the core weaknesses of Chongqing, Shanxi and Guizhou were in resource conservation, rural development and high output efficiency, respectively.

Table3. ranking of comprehensive indicators of agricultural green development of provinces and autonomous regions from 2010 to 2019

\begin{tabular}{|c|c|c|c|c|c|c|}
\hline Province & AGD & SR & OE & EF & GS & RD \\
\hline Shandong & 1 & 23 & 2 & 13 & 1 & 1 \\
\hline Beijing & 2 & 2 & 1 & 4 & 19 & 17 \\
\hline Zhejiang & 3 & 4 & 11 & 2 & 9 & 6 \\
\hline Fujian & 4 & 5 & 12 & 1 & 13 & 8 \\
\hline Jiangsu & 5 & 14 & 6 & 20 & 3 & 3 \\
\hline Heilongjiang & 6 & 15 & 13 & 26 & 2 & 2 \\
\hline Hainan & 7 & 7 & 14 & 3 & 30 & 7 \\
\hline Liaoning & 8 & 11 & 5 & 7 & 11 & 12 \\
\hline Hebei & 9 & 19 & 7 & 14 & 10 & 5 \\
\hline Guagdong & 10 & 10 & 19 & 5 & 15 & 13 \\
\hline Hubei & 11 & 25 & 15 & 16 & 4 & 9 \\
\hline Tianjin & 12 & 9 & 4 & 11 & 27 & 16 \\
\hline Shanghai & 13 & 13 & 3 & 6 & 20 & 24 \\
\hline Xinjiang & 14 & 1 & 17 & 22 & 23 & 15 \\
\hline Hunan & 15 & 29 & 20 & 15 & 6 & 14 \\
\hline
\end{tabular}




\begin{tabular}{|c|c|c|c|c|c|c|}
\hline Henan & 16 & 30 & 8 & 21 & 21 & 4 \\
\hline Inner Mongolia & 17 & 12 & 10 & 29 & 5 & 20 \\
\hline Ji lin & 18 & 18 & 9 & 18 & 18 & 19 \\
\hline Anhui & 19 & 27 & 16 & 19 & 7 & 18 \\
\hline Sichuan & 20 & 21 & 22 & 23 & 8 & 11 \\
\hline Guangxi & 21 & 16 & 28 & 12 & 22 & 10 \\
\hline Jiangxi & 22 & 26 & 26 & 9 & 12 & 21 \\
\hline Yunnan & 23 & 20 & 29 & 8 & 17 & 22 \\
\hline Gansu & 24 & 8 & 25 & 24 & 16 & 27 \\
\hline Shaanxi & 25 & 22 & 27 & 10 & 28 & 23 \\
\hline Ningxia & 26 & 3 & 21 & 28 & 25 & 26 \\
\hline Chongqing & 27 & 28 & 24 & 17 & 14 & 29 \\
\hline Qinghai & 28 & 6 & 18 & 30 & 26 & 25 \\
\hline Shanxi & 29 & 17 & 23 & 27 & 24 & 30 \\
\hline Guizhou & 30 & 24 & 30 & 25 & 29 & 28 \\
\hline
\end{tabular}

\section{Analysis on convergence of agricultural green development level}

\section{1 $\sigma$ convergence result}

Based on the principle of $\sigma$ convergence, this paper uses the coefficient of variation to measure the $\sigma$ convergence of China's agricultural green development level. Can be seen from the figure 1, in 2010-2019, while the coefficient of variation in the part of the year, picked up a little bit, but from the overall, the variation coefficient of the development level of China's agricultural green present the downward trend, suggesting that China's agricultural green development level convergence, there exists obvious sigma namely green agricultural development level gap between provinces in narrowing.

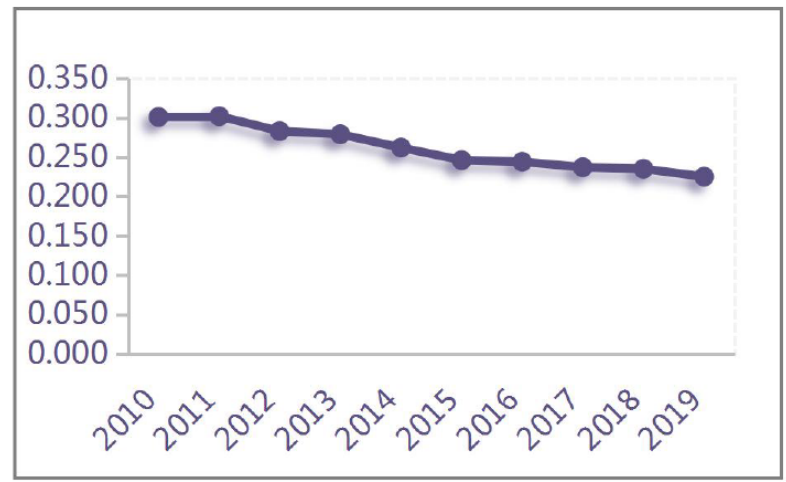

Figure 1. Coefficient of variation in the level of green agricultural development in China from 2010 to 2019.

\subsection{Absolute $\beta$ convergence results}

According to the test results in Table 4, the regression coefficient $\beta$ of the green development level of agriculture in the base period is $<0$ and significant at the $1 \%$ level, indicating that there is absolute $\beta$ convergence in the green development level of agriculture. This means that there is a "catch-up effect" in the level of agricultural green development between 2010 and 2019, that is, the trend of low-level developing provinces catching up with high-level developing provinces.

Table4. Absolute $\beta$ convergence test results of agricultural green development level

\begin{tabular}{|c|c|}
\hline$\alpha$ & $\begin{array}{c}-0.29^{* *} \\
(0.021)\end{array}$ \\
\hline$\beta$ & $-0.038^{* * *}$ \\
$(0.000)$
\end{tabular}

Note: $* * *, * *, *$ indicate significance at the level of $1 \%, 5 \%$ and $10 \%$, respectively. The $p$ value of each coefficient is shown in brackets.

\section{Conclusions and Suggestions}

\section{1 the conclusion}

1.Through the measurement of China's agricultural green development level and the provinces and autonomous regions, it is found that the overall level of agricultural green development in China shows a significant upward trend from 2010 to 2019. At the provincial level, there are obvious differences in the level of green agricultural development among provinces and regions. The regions with higher level of green agricultural development are mainly distributed in the eastern coastal areas and other developed regions, while the provinces and regions with lower level of development are mainly located in the western backward areas.

2.According to the analysis of the convergence model, there is not only significant $\sigma$ convergence but also significant absolute $\beta$ convergence in China's agricultural green development level from 2010 to 2019, which indicates that the gap of agricultural green development level among provinces and regions is gradually narrowing, that is, the provinces with lower development level catch up with the provinces with higher development level.

\subsection{Suggestions}

First, make up for their own shortcomings, implement the catch-up strategy, make use of the advanced technology, model and resource advantages of developed regions, form their own characteristics, and improve their own agricultural green development level. Second, promote inter-provincial exchanges and the further free flow of technologies, capital and information related to green agricultural development, so as to improve the overall level of green agricultural development. 


\section{References}

1. F.W.Yu . Research on Motivation, Core and Countermeasures of Agricultural Green Development in the New Era [J]. Chinese Rural Economy,05:19-34(2018)

2. H.J.Zhao , F.W.Yu . Evaluation of agricultural green development level in major grain producing areas based on entropy method [J]. Reform,11:136146(2019).

3. P.X.Jing, W.F.Zhao, Q. Zheng, D.H.Zhang . Research on dynamic prediction and path of agricultural green development level in Anhui Province [J]. Chinese Journal of Agricultural Resources and Regional Planning,39:51-56(2018).

4. J.Gao , Z.H.Ge . Analysis on regional difference and trend of agricultural green development level in Jiangsu Province [J]. Chinese Journal of Agricultural Resources and Regional Planning,41:14-22(2020).

5. Q.W. Gong, X.M.Li . Construction and measurement of agricultural green development index: 2005-2018 [J]. Reform, 01:133-145(2020).

6. S.M.Jin. Evaluation of China's provincial green agricultural development level and regional differences [J]. Probe, $02: 89-95(2019)$.

7. L Zhou . Study on green development of agriculture in Tibet under the background of rural revitalization [J]. Northwest Ethnic Studies,03:116-127(2019).

8. Q.WEI, B.Zhang, S.Q.Jin. Construction and regional comparison of China's agricultural green development index [J]. Issues in Agricultural Economy,11:11-20(2018).

9. L.L.Fu, X.H.Mao, B.B.Mao, H.T.Li. Study on the development of green agriculture in Zhejiang Province under the background of rural revitalization: Based on the perspective of comprehensive utilization of agricultural resources [J]. Chinese Journal of Agricultural Resources and Regional Planning,41:23-34(2020).

10. C.Y. Song, J.J.Zhang, L Liu, W.Q. Ma, L Ma, S. Ding, H.W. Zhao. Spatiotemporal changes of agricultural green development indicators in Hainan Island [J]. Chinese Journal of Eco-Agriculture,228:11561167(2020).

11. W.L Sun, R.b Wang, Q. Jiang, S.N. Huang. Study on connotation and evaluation of agricultural green development [J]. Chinese Journal of Agricultural Resources and Regional Planning,40:14-21(2019).

12. Y.Tian , J.B.Zhang. Research of Agricultural Modernization,34:85-89(2013).

13. N.M.Zhang, L.Zhang, H.Zhao, Y.C.Han, Y.H.Duan . Construction and application of agricultural green development evaluation index system [J]. Ecological Economy,34:21-24+46(2018).

14. Y.Z.Huang , X.F.Luo , Z.L.Li . Journal of China Agricultural University,22:183-190(2017).

15. S.J.Huang ,S.Y. Feng . Design and level measurement of agricultural green development indicators $[\mathrm{J}]$. Ecological Economy,37:125131(2021).

16. L.J.Wang, B.H.Jia, L.Y.Xin . Study on the driving factors of green agricultural development in Tianjin [J]. Chinese Journal of Agricultural Resources and Regional Planning,41:56-63(2020).

17. Baumol, W., Productivity, Growth, Convergence and Welfare:What the Long-run Da-ta Show[J], American Economic Review, 76, 1872 1885(1986).

18. Coulombe S., NewEvidence of Convergence Across Canadian Province:The Role of Urban-ization[J], Regional Studies, 34 , 713 725(1999).

19. Y.F.Lin, X.X.Liu, The Convergence of Economic Growth and Income Distribution in China [J], World Economy, 8 (2003).

20. Peng Guohua, The Analysis of Income Inequality, Total Factor Production and Its Convergence in China [J], Economic Research Journal, 9, (2005).

21. Strazicich, M.C., List, J.A., Are CO2emission levels converging among industrial countries-[J], Environmental and Resource Economics, 24, 263 271(2003).

22. Aldy, J.E., Per capita carbon dioxide emissions:convergence or divergence-[J], Environmental and Resource Economics, 33 , 533 555(2006).

23. K.Wang, H.Z.Song. Comparative analysis of three objective weighting methods $[\mathrm{J}]$. Technological Economics and Management Research,06:4849(2003).

24. C.Q.Tao , W.H.Chen, L.H.Lin . An Empirical Analysis of the Synergistic Degree of Industrial Organization Evolution in China: A Case Study of China's IT Industry under the Background of Enterprise Integration [J]. Management World,12:6772(2007).

25. D.Diakoulaki, G.Mavrotas and L.Papayannakis, 1995, Determining Objective Weight in Multiple Crireria Problems:The CRITIC method", Computer Ops Res, 22:763 770 .

26. Z.Wu , J.Guan, J.He . An Empirical Study on the Minimum Wage Standard: Dynamic Combination Calculation Based on CRIT-Entropy Weight Method $[\mathrm{J}]$. Contemporary Economic Science,41:103117(2019).

27. A.P.Zhang, Z.L.Peng, S.F.Wang, Y.Bai . The design principle and construction process of comprehensive evaluation index system [J]. Science Research Management,38:209-215(2017). 